\title{
REPRODUCTIVE BIOLOGY, HYBRIDIZATION, AND FLOWER VISITORS OF RARE SCLEROCACTUS TAXA IN UTAH'S UINTAH BASIN
}

\author{
Vincent J. Tepedino ${ }^{1,2}$, Terry L. Griswold ${ }^{1}$, and William R. Bowlin ${ }^{1,3}$
}

\begin{abstract}
We studied the mating system and flower visitors of 2 threatened species of Sclerocactus (Cactaceae) in the Uintah Basin of eastern Utah—an area undergoing rapid energy development. We found that both S. wetlandicus and S. brevispinus are predominantly outcrossed and are essentially self-incompatible. A third presumptive taxon (undescribed; here called S. wetlandicus-var1) is fully self-compatible but cannot produce seeds unless the flowers are visited by pollinators. We found tentative evidence for pollinator limitation of fruit set in S. brevispinus but not in the other taxa. Pollinators are largely species of native ground-nesting bees in the subfamily Halictinae. These bees are indiscriminate collectors of pollen and nectar from Sclerocactus flowers and other plant species. The well-being of Sclerocactus populations requires that land managers ensure the preservation of halictid bee habitat, which includes both nesting sites and a diversity of floral resources. These bees are also undoubtedly the pollen vectors responsible for the production of hybrids in areas where S. wetlandicus and S. brevispinus meet. We experimentally confirmed that reciprocal crosses between S. wetlandicus and S. brevispinus are indistinguishable from each other or from pure crosses in fruits/flower, seeds/fruit and seed weights. We suggest that hybridization preceded energy development, that it attests to the ongoing process of evolution in the Sclerocactus group, and that it should not be suppressed by anthropogenic activity.
\end{abstract}

Key words: Sclerocactus, pollination, breeding system, native bees, hybridization, conservation, Cactaceae.

The Uintah Basin of eastern Utah is currently undergoing considerable habitat modification due to energy development (oil and gas drilling, with oil shale extraction a future possibility; Federal Register 2007). Habitat modification removes extant plants and prospective sites for recruits, posing both direct and indirect problems for plants. Habitat destruction also lengthens the distance between populations, thereby isolating them and lowering the likelihood that they will maintain or increase their genetic variation by crossing with plants from other populations. The nesting habitat of potential pollinators is also removed as are alternate sources of pollen and nectar which may succor pollinators when their usual host plants are scant or absent.

Among the taxa threatened by this energy development are members of the genus Sclerocactus (Cactaceae), a group of barrel cacti restricted to western North America. The systematics of this genus is somewhat unsettled. The most recent revisions (Heil and Porter 2003, Hochstätter 2005) differ in the number of recognized species ( 15 and 10, respectively; Porter et al. [2007] put the present number at 22). To complicate matters further, Welsh et al. (2008) refer to earlier treatments of Sclerocactus as "amateurish and essentially worthless" and recognize only 3 species in Utah, compared to 7 by Heil and Porter (2003) and 6 by Hochstätter (2005).

Of especial interest here are 3 closely related taxa (Heil and Porter 2003): S. glaucus (K. Schumann) L.D. Benson, in western Colorado and in eastern Utah; S. wetlandicus Hochstätter; and S. brevispinus K.D. Heil \& J.M. Porter (called S. wetlandicus var. ilseae by Hochstätter [2005]). This systematic treatment by Heil and Porter (2003) is supported by recent studies of chloroplast DNA, AFLPs, and morphology (Porter et al. 2007). In contrast, Welsh et al. (2008) recognize glaucus and ilseae as varieties of S. whipplei and subsume wetlandicus as a misnomer under glaucus. All entities are rare; indeed, they are listed together as threatened under the Endangered Species Act under their former designation, $S$. glaucus.

The rarity of these taxa, coupled with the burgeoning energy development in their habitat calls for a better understanding of their

\footnotetext{
${ }^{1}$ Bee Biology and Systematics Laboratory, USDA-ARS, Department of Biology Utah State University, Logan, UT 84322-5310.

2E-mail: andrena@biology.usu.edu

${ }^{3}$ Present address: 2380 East 11000 North, Richmond UT 84333.
} 
TABle 1. Results of mating system experiments on 3 Sclerocactus taxa. Treatments: $\mathrm{X}=$ xenogamy, $\mathrm{G}=$ geitonogamy, $\mathrm{A}=$ autogamy, $\mathrm{C}=$ open-pollinated control, $\mathrm{N}=$ number of plants with flowers receiving treatments, $\mathrm{F}=$ number of fruits set, $\mathrm{N}_{\mathrm{S}}=$ Number of fruits used to obtain seed number and weight. $\mathrm{S} / \mathrm{F}=$ mean seeds per fruit, $\mathrm{SW}=$ average seed weight $(\mathrm{g}), \mathrm{SE}=$ standard error. Within each taxa, differing letters for $\mathrm{F}, \mathrm{S} / \mathrm{F}$, and $\mathrm{S} / \mathrm{W}$ indicate significant differences $\left(P<0.01 ; \chi^{2}\right.$ and Kruskal-Wallis tests, respectively).

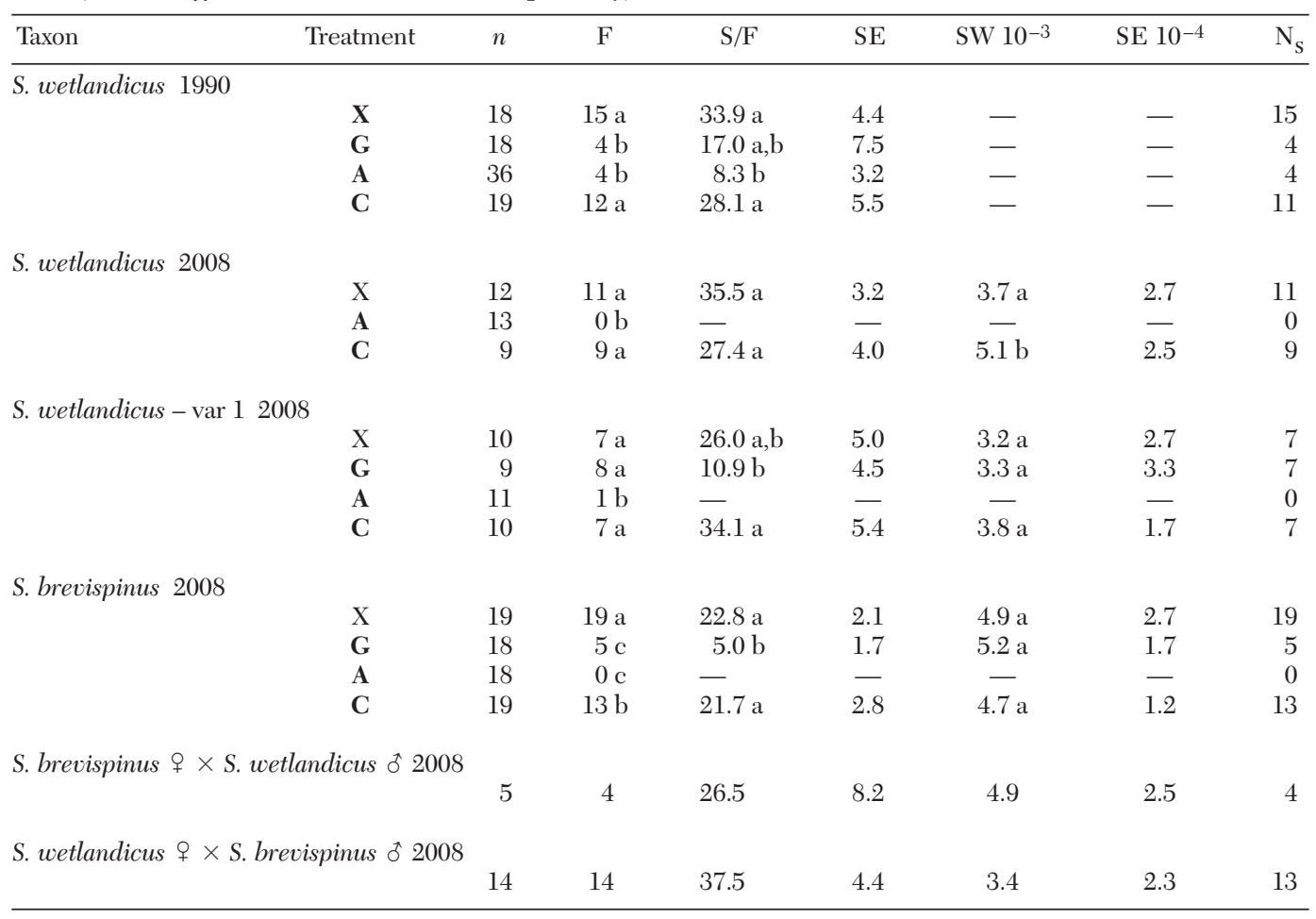

reproduction and systematics. The majority of flowering plants, including cacti (Grant and Grant 1979), depend on animals, especially insects, to effect seed production by carrying pollen to receptive stigmas (Axelrod 1960, Ricklefs and Renner 1994). Currently, no information exists on the breeding system or compatibility traits of any Sclerocactus species (contra Boyle 1997, which is in error). Information on potential pollinators is also absent.

Experimental evidence on the cross-compatibility of these Sclerocactus taxa is especially important because of the implications for conservation (Rieseberg 1991, Ellstrand and Elam 1993, Rhymer and Simberloff 1996). Heil and Porter (2003) reported that S. brevispinus hybridizes freely with S. wetlandicus along "a welldocumented cline." If hybridization can occur, as it does for many other taxa in the Cactaceae (Griffith 2003), then an additional threat appears: the genetic integrity of $S$. brevispinus is at risk of being compromised through swamping by the more widespread S. wetlandicus (Heil and
Porter 2003, Lambert et al. 2006, Reyes-Aguero et al. 2006).

Here we describe the breeding systems of S. brevispinus and S. wetlandicus, identify the common insect visitors to the flowers, and report results of preliminary reciprocal hybridization experiments. For each taxon, we ask the following questions: (1) Is seed production dependent on pollinator visitation to the flowers? (2) Can ovules be fertilized by self-pollen (i.e., are the taxa self-compatible)? (3) Is there any evidence that seed production is limited by insufficient pollinators? (4) What are the common flower visitors and are they shared by both taxa? (5) Are the taxa capable of hybridization, and if so, is hybridization symmetrical? Such information should help guide policies for the effective conservation of these taxa.

Finally, we also apply questions $1-4$ to a presumptive third taxon of Sclerocactus currently under study in the Uintah Basin, which we provisionally call "wetlandicus-varl." This isolated population occurs over several square 
miles to the northeast of $S$. wetlandicus sensu stricto. It can be separated from other S. wetlandicus by its consistently greater width-toheight ratio, flattened apex, and increased tendency to form multiple heads. In these characteristics (and others), it resembles $S$. brevispinus more than typical S. wetlandicus (D. Woodruff unpublished data).

\section{Methods}

We studied the same population of $S$. wetlandicus in 1990 (when it was included in S. glaucus) and in 2008, and we studied one population each of S. brevispinus and S. wetlandicus-varl in 2008. We withhold information on the locations of these populations because of the frequency of unscrupulous and illegal collection of plants (M. Ulloa personal communication). Exact locations have been shared with select members of federal and local agencies who also led us to these populations. General habitat descriptions are in Heil and Porter (2003; see also Federal Register 2007).

\section{Breeding System}

We studied the mating system of Sclerocactus taxa by initially selecting a variable number of treatment plants (Table 1) with 3 or more flower buds in each population and caging those plants shortly before flowers opened to exclude insects. To fully represent genetic diversity, we selected plants throughout each population. Wire cages were covered with 1-mm tulle and securely anchored to the substrate; they were kept in place at all times, except when flowers were being treated. Each plant received one or more of the following treatments: xenogamy (cross pollination using pollen donors at least several meters away from the recipient to reduce the chance of pollination by a close relative); geitonogamy (pollination with pollen from a different flower on the same plant); autogamy (unmanipulated, to test for automatic, unassisted self-pollination). Because of phenology and number of available flowers, it was not always possible to have all 3 treatments on each plant.

For the xenogamy and geitonogamy treatments, donor stamens with dehiscing anthers were rubbed across stigma lobes; pollen transfer was checked with a hand lens. One open, unmanipulated flower was selected from an adjacent plant with similar floral phenology to serve as a natural pollination control. Mature fruits were collected and filled seeds were counted; shriveled, misshapen seeds were recorded but were excluded from the subsequent analysis. After seeds air-dried for several months, weight of total seeds per fruit was determined with a microbalance accurate to $10^{-4} \mathrm{~g}$. Average seed weight was obtained by dividing total seed weight by the number of seeds in the fruit. Treatments were compared using the KruskalWallis test. Any departures from this protocol are noted in the results.

Chi-square contingency tables were used to test for a treatment effect on fruit set. Planned comparisons were (1) treatments requiring a pollen vector (xenogamy and geitonogamy) with treatments not requiring a vector (autogamy); (2) self-compatibility (geitonogamy) with outcrossing (xenogamy) treatments; and (3) experimental outcrossing (xenogamy) with the open-pollinated control to determine if "natural" fruit set is pollinator-limited.

In 1990, we estimated the number of pollen grains per anther by selecting a single plump anther from each of 14 flowers and preserving it in a previously prepared vial with a known quantity of $70 \%$ ethanol. In the laboratory, the anther was squashed and pollen grains dispersed by vigorous shaking. Pollen grains from each of several aliquots withdrawn from the vial were counted under a compound microscope at 200X; total number of grains per anther was adjusted to volume of ethanol in the vial, assuming complete dispersion (Kearns and Inouye 1993).

\section{Hybridization Experiments}

We conducted reciprocal hybridization experiments using one population each of $S$. wetlandicus and S. brevispinus. We chose populations that were as far apart as feasible (28.8 $\mathrm{km}$ ), taking into account population size (small populations were eliminated from consideration) and opportunities for access. Plants in each population were caged before flowers opened and recaged after treatment, as described above. At anthesis, cages were removed and dehiscing anthers of the donor species were rubbed across the stigma of the recipient. Pollen transfer was confirmed with a hand lens. Freshly dehiscing pollen was transferred in entire flowers, which were plucked from plants and kept in a cooler during transit between populations. The entire process, from flower plucking to 
pollination, never took more than a few hours. Other studies have shown that cactus pollen maintained under cool conditions will last for several days (Chapman et al. 2002). Fruits were treated as described previously.

\section{Flower Visitors}

Foraging insects were captured opportunistically in 1990 and 2008 as one or more collectors walked among plants with open Sclerocactus flowers. In 2008, we spent 3.5 hours collecting from $S$. brevispinus flowers, 4 hours from S. wetlandicus flowers, and 2 hours from $S$. wetlandicus-varl flowers. We purposely collected on a limited schedule to minimize our effect on the reproductive success of Sclerocactus plants. Collecting from S. wetlandicus in 1990 was equally opportunistic, occurring as time allowed.

In 2008, we spent over 6.5 hours observing the behavior of bees as they visited Sclerocactus flowers. Individual observations were grouped by bee genus because of the difficulty of distinguishing species without capture and subsequent examination in the laboratory. Collected insects were killed, pinned, labeled, and returned to the Bee Biology and Systematics Laboratory, Logan, Utah, for identification and deposition. The bodies of collected bees were examined under a binocular microscope at $80 \mathrm{X}$ for large, distinct cactus pollen grains. Using the method of Beattie (1971), we also examined slides with pollen sampled from the scopa of pollen-collecting females, and we recorded the presence of cactus pollen.

\section{Results}

\section{Sclerocactus wetlandicus}

FLOWER DEVELOPMENT.-Flowers typically open between 11:00 and 13:00 and close between 18:00 and 20:00 for 3 days (during cold spells, they may open for 5 consecutive days). The time of opening and closing may depend on temperature and/or illuminance.

On opening, petals are bright pink with cream-colored edges and streaks. The petals gradually lose color on subsequent days until by the last day of anthesis they are pale with only a faint tinge of pink. Initially, stamens are appressed to the style and to each other. As the first day wears on, the stamens straighten and are all erect by late afternoon. The bright yellow anthers dehisce in concentric groups.
The outermost ring, with the longest filaments, dehisces first as the flower initially opens and is followed by more interior anther rings on subsequent days. Thus, fresh pollen is available each morning. On average, anthers each produce 317.7 pollen grains ( $\mathrm{SE}=31.2, n=14$ ).

The stigma is cylindrical (usually with 6 ribs) and is, together with the style, a light pink to flesh color when fresh, becoming a darker pink with age. The flowers are most fragrant on the first day of opening and become less so on subsequent days, until the odor disappears on the last day.

The perianth is persistent on the forming fruit, which begins to swell about 2 weeks after the blossom has dried. Upon reaching maturity (approximately 4-5 weeks), the fruit develops a suture line about the base, and the walls fall off leaving the seeds in a small pile among the spines at the top of the plant. Vigorous rain showers wash the seeds to the ground and appear to be the main method of seed dispersal. Most young seedlings were found beside putative parent plants.

Mating SYstem: Fruits._Data from 1990 and 2008 were mostly congruent. Few if any fruits or seeds were produced in the autogamy treatment, suggesting that pollinators are necessary for successful sexual reproduction (1990: $\chi^{2}=14.4, \mathrm{df}=2, P<0.001 ; 2008: \chi^{2}=12.2$, $\mathrm{df}=1, P<0.001$; Table 1). In 1990, significantly fewer fruits and seeds were produced in the geitonogamy treatment than in the xenogamy treatment $\left(\chi^{2}=15.5\right.$, df $=1, P<$ 0.001 ; geitonogamy treatments were not conducted in 2008). This finding shows that selfcompatibility in $S$. wetlandicus is very low, assuming that the few fruits and seeds produced geitonogamously were not the result of contamination. Finally, in neither year was there a significant difference between the xenogamy treatment and the open-pollinated control in fruit set (1990: $\chi^{2}=1.9$, df $=1, P>0.10$; 2008: $\chi^{2}=0.65$, df $\left.=1, P>0.10\right)$ or seed production, suggesting that pollinator visits to the flowers were not limiting.

Mating System: SEEDS.-Seeds per fruit differed significantly among the 3 treatments in 1990 and between xenogamy and autogamy in 2008 (Table 1). In 1990, the selfing treatments (autogamy and geitonogamy) produced fewer seeds per fruit than did the outcrossing treatments (xenogamy and control), although only the autogamy treatment comparison was 
TABLE 2. Occurrence of bee species on the flowers of Sclerocactus in the Uintah Basin, 1990 and 2008 . BR08 is a S. brevispinus (2008) site; BonWet is the S. “wetlandicus - var. 1" site (2008); W90 is a S. wetlandicus site from 1990; W108, W208, W308 are 3 S. wetlandicus sites from 2008. Sampling effort varied from year to year and from site to site, depending on time and subjective impression of the number of bees on the flowers: the fewer bees seen, the less the collecting effort. Some individuals of bee taxa at sites marked with Xp were collecting pollen; individuals at sites marked with $\mathrm{X}^{\mathrm{B}}$ carried cactus pollen scattered over their bodies.

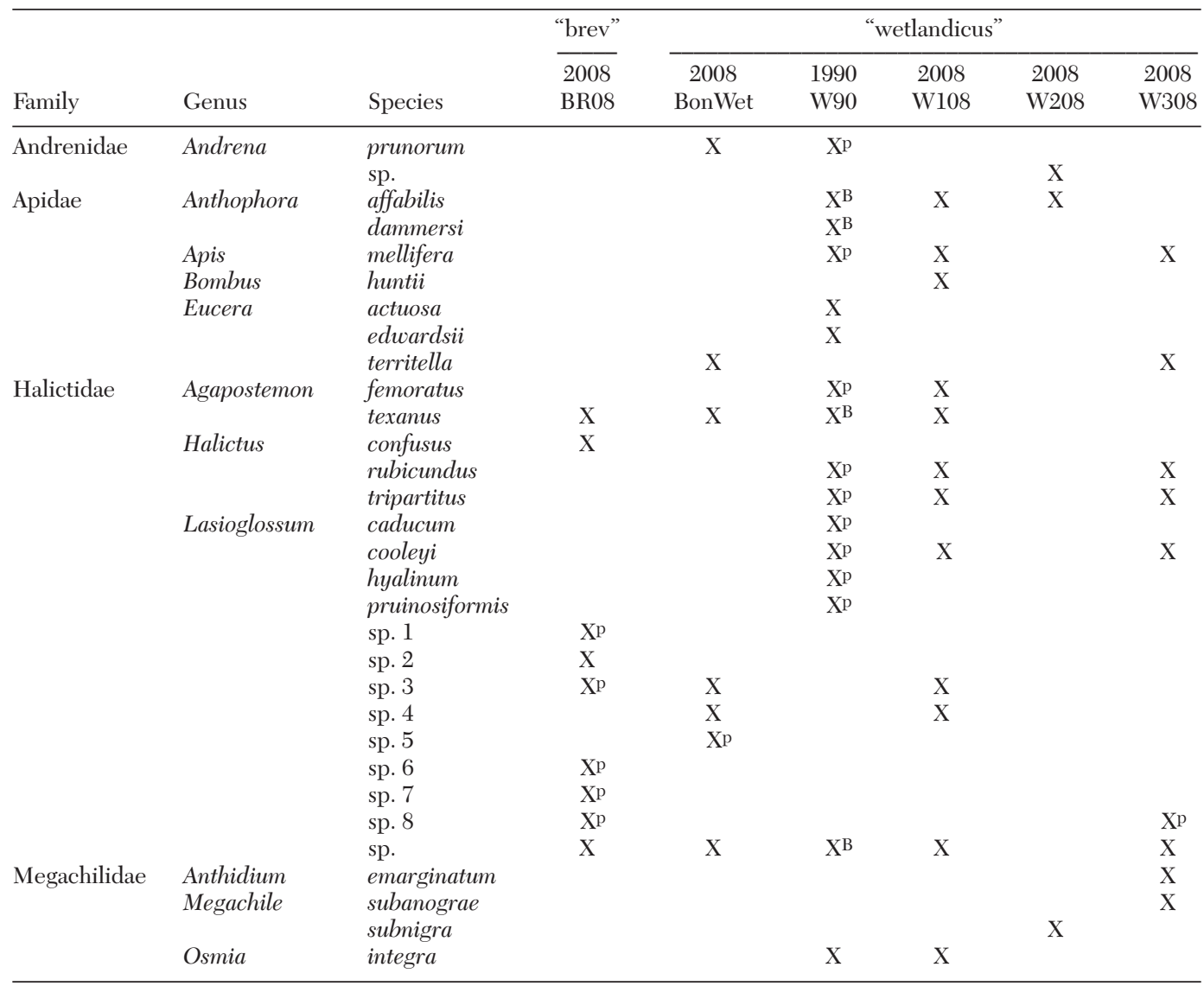

significant. No significant difference existed among the other 3 treatments.

\section{Sclerocactus wetlandicus-var1}

Mating System: FRUITS.-Results from the pollination treatments of S. wetlandicus-var1 differed somewhat from those of S. wetlandicus (Table 1). Both taxa had almost no fruit set without pollen transfer by a vector $\left(\chi^{2}=14.3\right.$, $\mathrm{df}=2, P<0.001)$. However, flowers of $S$. wetlandicus-varl were highly self-compatible; indeed, there was no significant difference in fruit set between the xenogamy and geitonogamy treatments $\left(\chi^{2}=0.7, \mathrm{df}=1, P>0.10\right)$ or between xenogamy and open-pollinated control treatments $\left(\chi^{2}=0.0, \mathrm{df}=1, P>0.10\right)$. Thus, pollinators are required, interflower movements on the same plant are likely to produce fruits, and there is no evidence that scarcity of pollinators limits fruit set.

Mating SYSTEM: SEEDS.-Fruits that were the products of self-pollination had significantly fewer seeds than did xenogamy or open-pollinated control treatments (Table 1). The latter 2 treatments did not differ significantly. Average seed weight did not differ significantly among the 3 treatments.

\section{Sclerocactus brevispinus}

MATING SYsTeM: FRUITS.-As with the preceding taxa, fruits of S. brevispinus are not produced unless flowers are visited by a pollen vector $\left(\chi^{2}=13.0, \mathrm{df}=2, P<0.001\right.$; Table 1$)$. Flowers receiving within-plant selfing treatments (geitonogamy) produced significantly fewer fruits than flowers receiving xenogamy 
treatments $\left(\chi^{2}=6.9, \mathrm{df}=1, P<0.01\right)$. In contrast to other taxa, fruit set differed significantly between the xenogamy and open-pollinated control treatments $\left(\chi^{2}=7.1, \mathrm{df}=1, P\right.$ $<0.01$ ), suggesting that pollinators can be limiting at times.

Mating system: SeEds.-We found significantly fewer seeds per fruit in the geitonogamy treatment than in the xenogamy and open-pollinated control treatments (Table 1). The latter 2 did not differ significantly. Average seed weight did not differ significantly among the treatments.

\section{Hybridization}

SCLEROCACTUS BREVISPINUS $9 \times$ SCLEROCACTUS WETLANDICUS o $^{\top}$.-F Four of $5 \mathrm{~S}$. brevispinus flowers set fruit when pollinated by S.wetlandicus pollen donors (Table 1). The number of seeds per fruit did not differ significantly between this hybridization treatment and the within-taxa S. brevispinus xenogamy and openpollinated controls (Kruskal-Wallis test, $P>$ $0.60)$. Nor was there a significant difference in average seed weight among these 3 treatments (Kruskal-Wallis test: $P>0.60$ ).

SCLEROCACTUS WETLANDICUS $q \times$ SCLEROCACTUS BREVISPINUS ô.-All 14 treated flower hybridizations set fruit (Table 1). Numbers of seeds per fruit did not differ significantly among the hybrid treatment and the within-taxa $S$. wetlandicus treatments of xenogamy and openpollinated controls (Kruskal-Wallis test, $P=$ $0.15)$. Control seeds were significantly heavier than those of the xenogamy or hybridization treatments (Kruskal-Wallis test: $P<0.001$ ).

Cross hybrid Comparisons.-There were no significant differences between the crosses in number of seeds per fruit (Kruskal-Wallis test: $P>0.20$; Table 1 ). Seeds did differ in weight according to female parent: seeds from fruits whose maternal parent was S. brevispinus were significantly heavier than those whose maternal parent was S. wetlandicus (KruskalWallis test: $P<0.01$ ).

\section{Sclerocactus Flower Visitors}

We collected 31 taxa of bees visiting the flowers of Sclerocactus taxa in the 2 years of study (Table 2). Over half of the taxa (18 species) were sweat bees (Halictidae); 13 species belonged to the genus Lasioglossum. Twentysix species were collected visiting S. wetlandicus, and 9 were collected visiting $S$. brevispinus
(4 halictid species were common to both cactus taxa).

Bee faunas were very similar between years and among sites (Table 2). For example, 10 of the 16 species collected on S. wetlandicus in $1990(62.5 \%)$ were also found on S. wetlandicus in 2008. In 2008, 10 of the 20 species collected from the $3 \mathrm{~S}$. wetlandicus sites were present at more than one site. Additionally, 4 of the 9 species captured in limited collecting on $S$. brevispinus in 2008 were also visitors of $S$. wetlandicus flowers.

Bees most commonly observed were female Lasioglossum, followed by a few Agapostemon and Andrena prunorum. Behavior of all females was similar: they typically landed on the anthers (sometimes on the petals and occasionally on the stigma), then almost always descended, head foremost, into the flower, where their behavior was obscured because of their small size and the thigmotactic stamens which closed over them, presumably as they collected nectar. Most specimens carried Sclerocactus pollen (Table 2). Individuals of 19 of the 31 bee species either had cactus pollen in their scopae (15 species) or scattered over their bodies (4 species). Five of these species, all of the genus Lasioglossum, visited S. brevispinus flowers, whereas 15 visited S. wetlandicus (7 species of Lasioglossum).

\section{Discussion}

Land managers charged with conserving rare Sclerocactus populations in the Uintah Basin are faced with complicated and novel problems, if their goal is to maintain natural processes and the evolutionary potential of these taxa. In addition to dealing with predictable impacts from energy development-like modification, fragmentation, and destruction of rare-species habitat-managers must also (1) address pollinator conservation, (2) permit continued hybridization and potential introgression between $S$. brevispinus and S. wetlandicus, and (3) recognize, and possibly protect, an additional, undescribed endemic taxon (provisionally $S$. wetlandicus-var1; D. Woodruff unpublished data).

Our studies clearly show that pollinators are necessary for successful sexual reproduction by Sclerocactus. For each of these 3 Sclerocactus entities, as well as S. wrightii and S. mesaeverdae (Tepedino unpublished data) and many 
other species of cacti (Grant and Grant 1979, Ross 1981, Nerd and Mizrahi 1997, PimientaBarrios and del Castillo 2002), seeds are not produced unless pollen is moved between flowers by bees (Tables 1, 2). For all 3 taxa studied here, significantly more seeds were produced when flowers were outcrossed (Table 1) than when they were selfed. The most parsimonious explanation of the few fruits and seeds produced in geitonogamous crosses within both $S$. brevispinus and S. wetlandicus is contamination of self-pollen with outcross pollen, although it is possible that a low frequency of self-compatibility is present in the population. Only the unusual population of S. wetlandicus-varl consistently produced seeds from pollinator-assisted self-pollinations.

The bees that frequent the flowers of Sclerocactus (Table 2 ) are primarily ground-nesting species of the subfamily Halictinae. They appear to visit the flowers of the 3 taxa indiscriminately. Many species that visited cactus flowers in 1990 also did so in 2008, and many species that visited S. wetlandicus did so at more than one site and also visited S. brevispinus and S. wetlandicus-varl. Surprisingly, we found none of the flower-visiting bee specialists in Diadasia, Lithurgus, or other bee genera that are closely associated with other cactus taxa with similar flowers (e.g., Opuntia; Grant and Hurd 1979). This is a curious but apparently robust finding, for these cactus specialists were also absent from the flowers of $S$. wrightii and S. mesae-verdae (Tepedino unpublished data).

Bee numbers currently appear to be large enough to pollinate all or most Sclerocactus flowers in the Uintah Basin. Only for S. brevispinus was there a suggestion that open-pollinated flowers produced significantly fewer fruits per flower than did hand-outcrossed flowers (Table 1). This evidence for pollinator limitation is weak for 2 reasons: (1) the sample size of experimental flowers was only moderate; and (2) within-plant competition among maturing fruits for presumably limited resources was likely more intense among flowers of uncaged, open-pollinated plants than among flowers of caged plants, not all of which were pollinated (Zimmerman and Pyke 1988). Thus, our finding of pollinator limitation of seed production in $S$. brevispinus is tentative and should be replicated.

Conserving Sclerocactus populations requires protecting those resources necessary for healthy, sustainable bee populations. Unlike most inects, bees expend much effort in constructing nests and collecting flower nectar and pollen to rear their offspring. More detailed information on the nesting habitat of these particular cactus-frequenting species is not available, but it is likely that their nests, as for most halictines of arid regions, are located in flat, sparsely vegetated soil with good drainage (Sakagami and Michener 1962, Plateaux-Quénu 1972). To prevent loss of bee habitat, prospective oil and gas pads and well sites should be inspected for the presence of both rare cacti (Federal Register 2007) and bee nests. Well sites should be located in areas without Sclerocactus plants and bee nests, or where nests can be protected from heavy traffic and extraction activities. Moderate energy extraction is not necessarily incompatible with the continued existence of Sclerocactus and its pollinators in the Uintah Basin, though profligate and careless energy extraction certainly is.

Protecting habitat for halictine bees also means managing for abundance and diversity of flower species (Tepedino et al. 1997). Most members of the subfamily Halictinae visit a wide variety of flowers (Moure and Hurd 1987) which they use both when Sclerocactus is in bloom and when it is not. Thus any general habitat deterioration that would substantially reduce native flower abundance and diversity would have an adverse effect on bee populations and must be avoided.

The "blessing" of bees confers with it a potential "curse" of hybridization for closelyrelated (Porter et al. 2007), sympatric-parapatric congeners, such as S. brevispinus and $S$. wetlandicus. Hybrid zones and clines have been reported in several areas of contact between these taxa (Heil and Porter 2003, Porter et al. 2007, Woodruff personal communication), and we have clearly shown that they are fully and reciprocally cross-compatible (Table 1), at least with respect to fruits per flower and seeds per fruit (tests of seed germination are currently underway). The generalized foraging behavior of individual halictine bees strongly implicates them as the primary agents of Sclerocactus hybridization. But is hybridization a threat to the integrity of these taxa or is it best viewed as part of the ongoing evolutionary process? And how should land managers approach this situation?

Hybridization is often a contentious issue, both for conservationists (Allendorf et al. 2001, 
Campton and Kaeding 2005) and for evolutionary biologists (Rieseberg 1991, Ellstrand and Elam 1993, Rhymer and Simberloff 1996, Arnold 1997, 2006). Here it may be doubly so because, unlike most situations in which only one participating species at most is rare, both S. brevispinus and S. wetlandicus are rare. Indeed, both are listed as threatened because $S$. glaucus, from which they were recently separated, is listed as threatened (Federal Register 2007); their hybrids are also protected.

Currently, there are 2 contrasting interpretations of situations in which native taxa of different population sizes interbreed. One is that the minority species, in this case S. brevispinus (approximately 8000 individuals; Federal Register 2007), is in danger of being engulfed by the majority species, here $S$. wetlandicus (Federal Register 2006). This could occur either by introgression, in which case the engulfer would incorporate some genetic material of the engulfee, or by wasting the pollen and ovules of the minority species in infertile, interspecific matings with the majority species. Alternatively, Rhymer and Simberloff (1996), Arnold (1997, 2006), Barton (2001), Baack and Rieseberg (2007), and others have argued that such hybridization events can genetically enrich either or both participants and that hybridization is an integral part of the evolutionary process — one that should not be suppressed (Myers and Knoll 2001, but see Barraclough and Davies 2005). At this point we do not know the frequency of Sclerocactus hybrids and the extent of their distribution. We also do not know if hybrids are fertile and adapted to some intermediate microhabitat or if introgression is occurring. Such questions must be addressed if we are to understand evolutionary developments in this taxon and how to manage Sclerocactus populations.

To manage Sclerocactus in the Uintah Basin, land managers must understand if hybridization is natural or if it is being precipitated by habitat disturbance caused by energy development. Of the 3 reasons cited by Rhymer and Simberloff (1996) for hybridization impelled by habitat change, 2 anthropogenic disturbances - the sudden creation of connecting corridors between taxa and "hybridization of the habitat" (Anderson 1948)_-may fit the circumstances found in the Uintah Basin. Although energy development may separate taxa by destroying habitat, it may also draw congeners together by creating colonization opportunities for hybrids in disturbed areas. For example, roadbuilding and roads may provide unique habitat that becomes colonized disproportionately by introgressed individuals (Levin et al. 1996, Brochmann et al. 2000, Baggs and Maschinski 2001) which then pave the way to the genetic swamping of the minority species.

Alternatively, it is quite possible that range expansion by one or both Sclerocactus taxa predated energy development. These 2 recently separated taxa (Porter et al. 2007) may have evolved in allopatry (with the free movement of bees between taxa, it is hard to envision a sympatric origin), each adapting to slightly different microhabitats-S. wetlandicus to coarser and perhaps drier soil substrates (usually at or near butte tops) and S. brevispinus to finer, perhaps wetter, more low-lying areas (Federal Register 2006). From there, they have now expanded into contact and hybridization. However, until we have demographic and genetic evidence to separate the natural and disturbance causes for hybridization, land managers should do nothing to halt the ongoing evolutionary process in this group.

Finally, the status of S. wetlandicus-varl should be addressed. Morphological measurements suggest a distinct taxon (D. Woodruff personal communication), but molecular genetic studies are less persuasive (J.M. Porter personal communication). This entity shares several characteristics with polyploids. In the Cactaceae, polyploids tend to be larger and to branch more than diploids. They are also more likely to be self-compatible (Ross 1981, Barringer 2007). These are all characteristics of $S$. wetlandicus-var1. Thus, we hypothesize that $S$. wetlandicus-varl is an autopolyploid of $S$. wetlandicus.

\section{ACKNOWLEDGMENTS}

We had much help on this project. At USDI-BLM, Utah, hats off to Maria Ulloa and Ron Bolander for suggesting and funding the project. Botanicas Extraordinarias Jessie Salix, M. Ulloa (BLM), and Beth Chester (USFWS) were unstinting with their help in the field, in the office, and with logistics. Harold Ikerd, USDA-ARS, carried out most of the fieldwork in his typical "can-do" fashion. The manuscript benefited from reviews by J. Mark Porter, J. Salix, M. Ulloa, and D. Woodruff. 


\section{Literature Cited}

Allendorf, F.W., R.F. Leary, P. Spruell, and J.K. WenBURG. 2001. The problems with hybrids: setting conservation guidelines. Trends in Ecology and Evolution 16:613-622.

Anderson, E. 1948. Hybridization of the habitat. Evolution 2:1-9.

ARNOLD, M.L. 1997. Natural hybridization and evolution. Oxford University Press, New York, NY.

2006. Evolution through genetic exchange. Oxford University Press, New York, NY.

AXELROD, D.I. 1960. The evolution of flowering plants. Pages 227-305 in S. Tax, editor, Evolution after Darwin. Volume 1, The evolution of life. University of Chicago Press, Chicago, IL.

BaAcK, E.J., AND L.H. RieseberG. 2007. A genomic view of introgression and hybrid speciation. Current Opinion in Genetics and Development 17:513-518.

BAGGS, J.E., AND J. MASCHINSKI. 2001. The threat of increasing hybridization of an endangered plant species, Purshia subintegra, in the Verde Valley, Arizona. Pages 213-220 in Southwestern Rare and Endangered Plants: Proceedings of the Third Conference; 2000 September 25-28; Flagstaff, AZ. Proceedings RMRSP-23, Rocky Mountain Research Station, USDA Forest Service, Fort Collins, CO.

Barraclough, T.G., and T.J. Davies. 2005. Predicting future speciation. Pages 400-418 in A. Purvis, J.L. Gittleman, and T. Brooks, editors, Phylogeny and conservation. Cambridge University Press, New York, NY.

BARRINGER, B.C. 2007. Polyploidy and self-fertilization in flowering plants. American Journal of Botany 94 1527-1533.

BARTON, N.H. 2001. The role of hybridization in evolution. Molecular Ecology 10:551-568.

Beattie, A.J. 1971. A technique for the study of insectborne pollen. Pan-Pacific Entomologist 47:82

BoyLe, T.H. 1997. The genetics of self-incompatibility in the genus Schlumbergera (Cactaceae). Journal of Heredity 88:209-214.

Brochmann, C., L. Borgen, And O.E. Stabbetorp. 2000 Multiple hybrid speciation of the Canary Island endemic Argyranthemum sundingii (Asteraceae). Plant Systematics and Evolution 220:77-92.

Campton, D.E., And L.R. KaEding. 2005. West slope cutthroat trout, hybridization, and the U.S. Endangered Species Act. Conservation Biology 19:1323-1325.

Chapman, B., J.C. Mondragon, R.A. Bunch, and A.H. Paterson. 2002. Breeding and biotechnology. Pages 255-271 in P.S. Nobel, editor, Cacti: biology and uses. University of California Press, Berkeley, CA.

Ellstrand, N.D., AND D.R. Elam. 1993. Population genetic consequences of small population size: implications for plant conservation. Annual Review of Ecology and Systematics 24:217-242.

Federal Register. 2006. 50 CFR Part 17. Endangered and threatened wildlife and plants; 90-day finding on a petition to remove the Uinta Basin hookless cactus from the list of endangered and threatened plants; 90-day finding on a petition to list the Pariette cactus as threatened or endangered. Federal Register 71:75215-75220.

2007. 50 CFR Part 17. Endangered and threatened wildlife and plants; 12-month finding on a petition to list Sclerocactus brevispinus (Pariette cactus) as an endangered or threatened species; taxonomic change from Sclerocactus glaucus to Sclerocactus brevispinus, S. glaucus and S. wetlandicus. Federal Register 72(180):53211-53222.

Grant, V., and K.A. Grant. 1979. The pollination spectrum in the southwestern American cactus flora. Plant Systematics and Evolution 133:29-37.

Grant, V., AND P.D. Hurd. 1979. Pollination of southwestern opuntias. Plant Systematics and Evolution 133: $15-28$.

Griffith, M.P. 2003. Using molecular evidence to elucidate reticulate evolution in Opuntia (Cactaceae). Madroño 50:162-169.

Heil, K.D., AND J.M. PoRTER. 2003. 22. Sclerocactus. Pages 197-207 in Editorial Committee, editors, Flora of North America. Volume 4, Magnoliophyta: Caryophyllidae, part 1. Oxford University Press, New York, NY.

Hochstätter, F. 2005. The genus Sclerocactus. Tribe Cacteae. Family Cactaceae. Translated by C. Holland. Published privately. Available from: http:// fhnavajo.com

Kearns, C.A., and D.W. Inouye. 1993. Techniques for pollination ecologists. University Press of Colorado, Niwot, CO.

Lambert, S.M., E.L. Borba, M.C. Machado, and S.C. Da Silva Andrade. 2006. Allozyme diversity and morphometrics of Melocactus paucispinus (Cactaceae) and evidence for hybridization with $M$. concinnus in the Chapada Diamantina, Northeastern Brazil. Annals of Botany 97:389-403.

Levin, D.A., J. Franciso-Ortega, and R.K. Jansen. 1996. Hybridization and the extinction of rare plant species. Conservation Biology 10:10-16.

Moure, J.S., AND P.D. HuRD JR. 1987. An annotated catalog of halictid bees of the Western Hemisphere. Smithsonian Institution Press, Washington, DC

Myers, N., AND A.H. KNOLL. 2001. The biotic crisis and the future of evolution. Proceedings of the National Academy of Sciences (USA) 98:5389-5392.

Nerd, A., AND Y. MizRahi. 1997. Reproductive biology of cactus fruit crops. Horticultural Reviews 18:321-346.

Pimienta-Barkios, E., and R.F. Del Castillo, 2002. Reproductive biology. Pages 75-90 in P.S. Nobel, editor, Cacti: biology and uses. University of California Press, Berkeley, CA.

PlateauX-Quénu, C. 1972. La biologie des abeilles primitives. Masson, Paris

Porter, J.M., J. Cruse-Sanders, L. Prince, and R. Lauri. 2007. As assessment of genetic relationships among Sclerocactus brevispinus, S. wetlandicus and S. glaucus. Unpublished report, U.S. Fish and Wildlife Service, Salt Lake City, UT. 30 pp.

Reyes-Aguero, J.A., J.R. Aguirke, and A. ValienteBANUET. 2006. Reproductive biology of Opuntia: a review. Journal of Arid Environments 64:549-585.

Rhymer, J.M., AND D. SimberLofF. 1996. Extinction by hybridization and introgression. Annual Review of Ecology and Systematics 27:83-109.

Ricklefs, R.E., AND S.S. RENNER. 1994. Species richness within families of flowering plants. Evolution 48: 1619-1636.

RieseberG, L.H. 1991. Hybridization in rare plants: insights from case studies in Cercocarpus and Helianthus. Pages171-181 in D.A. Falk and K.E. Holsinger, editors, Genetics and conservation of rare plants. Oxford University Press, New York, NY. 
Ross, R. 1981. Chromosome counts, cytology, and reproduction in the Cactaceae. American Journal of Botany 68:463-470.

SaKagami, S.F., And C.D. Michener. 1962. The nest architecture of the sweat bees. University of Kansas Press, Lawrence, KS.

Tepedino, V.J., S.D. Sipes, J.L. Barnes, AND L.L. HickerSON. 1997. The need for "extended care" in conservation: examples from studies of rare plants in the Western United States. Acta Horticulturae 437: 245-249.
Welsh, S.L., N.D. ATwood, S. Goodrich, and L.C. HigGINS, EDITORS. 2008. A Utah flora. 4th edition. Brigham Young University, Provo, UT.

Zimmerman, M., And G.H. Pyke. 1988. Reproduction in Polemonium: assessing the factors limiting seed set. American Naturalist 131:723-738.

Received 8 May 2009 Accepted 7 December 2009 